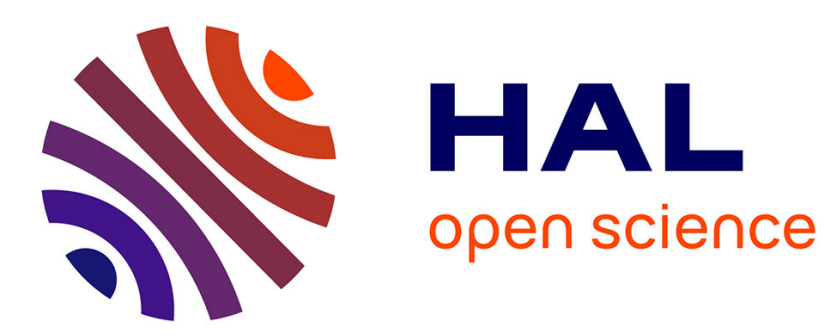

\title{
Mechanical Behavior of Side-Chain Liquid Crystalline Networks
}

\author{
J. Gallani, L. Hilliou, P. Martinoty, F. Doublet, Monique Mauzac
}

\section{To cite this version:}

J. Gallani, L. Hilliou, P. Martinoty, F. Doublet, Monique Mauzac. Mechanical Behavior of Side-Chain Liquid Crystalline Networks. Journal de Physique II, 1996, 6 (3), pp.443-452. 10.1051/jp2:1996190 . jpa-00248307

\section{HAL Id: jpa-00248307 https://hal.science/jpa-00248307}

Submitted on 1 Jan 1996

HAL is a multi-disciplinary open access archive for the deposit and dissemination of scientific research documents, whether they are published or not. The documents may come from teaching and research institutions in France or abroad, or from public or private research centers.
L'archive ouverte pluridisciplinaire HAL, est destinée au dépôt et à la diffusion de documents scientifiques de niveau recherche, publiés ou non, émanant des établissements d'enseignement et de recherche français ou étrangers, des laboratoires publics ou privés. 


\title{
Mechanical Behavior of Side-Chain Liquid Crystalline Networks
}

\author{
J.L. Gallani $\left({ }^{1}\right)$, L. Hilliou $\left({ }^{1}\right)$, P. Martinoty $\left({ }^{1, *}\right)$, F. Doublet $\left({ }^{2}\right)$ \\ and M. Mauzac $\left({ }^{2}\right)$ \\ (1) Laboratoire d'Ultrasons et de Dynamique des Fluides Complexes, Université Louis Pasteur. \\ 4 rue Blaise Pascal, 67070 Strasbourg Cedex, France \\ $\left({ }^{2}\right)$ Centre de Recherche Paul Pascal, CNRS, Domaine Universitaire, \\ Avenue du Docteur Schweitzer, 33600 Pessac, France
}

(Received 31 July 1995, received in final form 11 December 1995, accepted 12 December 1995)

PACS.61.30.-v - Liquid crystals
PACS.83.20.Dr - Elastomeric polymers
PACS.61.41.te - Polymers, elastomers, and plastics

\begin{abstract}
The mechanical properties of a homologue series of side-chain mesomorphic networks were studied with a piezo-rheometer over frequencies ranging from $10^{-2} \mathrm{~Hz}$ to $10^{4} \mathrm{~Hz}$. The results show that the compound's response is governed essentially by the dynamic glass transition. It is sensitive to the N-SmA transition, but insensitive to the N-I transition, with the result that the empirical principle of time-temperature superposition can be applied throughout the N-I transition. The influence of the crosslinking density and the amount of mesogenic side groups was also studied. For each of the samples, the static rigidity modulus $G_{0}$, the infinite-frequency dynamic rigidity modulus $G_{\infty}$, and the characteristic frequencies respectively associated with the longest visco-elastic mode and with the glass transition, were determined.
\end{abstract}

Résumé. - Les propriétés mécaniques d'une série homologue de réseaux mésomorphes à chaînes latérales ont été étudiées avec un piézo-rhéomètre entre $10^{-2} \mathrm{~Hz}$ et $10^{4} \mathrm{~Hz}$. Les résultats obtenus montrent que la réponse du matériau est essentiellement gouvernée par la transition vitreuse dynamique; elle est sensible à la transition N-SmA mais insensible à la transition N-I de sorte qu il est possible d'appliquer le principe empirique de superposition temps-température au travers de la transition $\mathrm{N}$-I. L'influence du taux de réticulation et du taux de mésogènes a également été étudiée. Le module de rigidité statique $G_{0}$, le module de rigidité dynamique à fréquence infinie $G_{\infty}$ et les fréquences caractéristiques associées respectivement au mode viscoélastique le plus long et à la transition vitreuse, ont été déterminées pour chaque échantillon.

\section{Introduction}

Mesomorphic networks constitute a new class of materials, combining the elastic properties of conventional elastomers and those of liquid crystals. These materials have been the object of numerous studies in recent years [1], and a certain number of interesting properties have been observed, such as, for instance, the occurrence of a macroscopic orientation of the mesogens when the sample is subjected to a static mechanical stress. On the other hand, very few

$\left(^{*}\right)$ Author for correspondence 


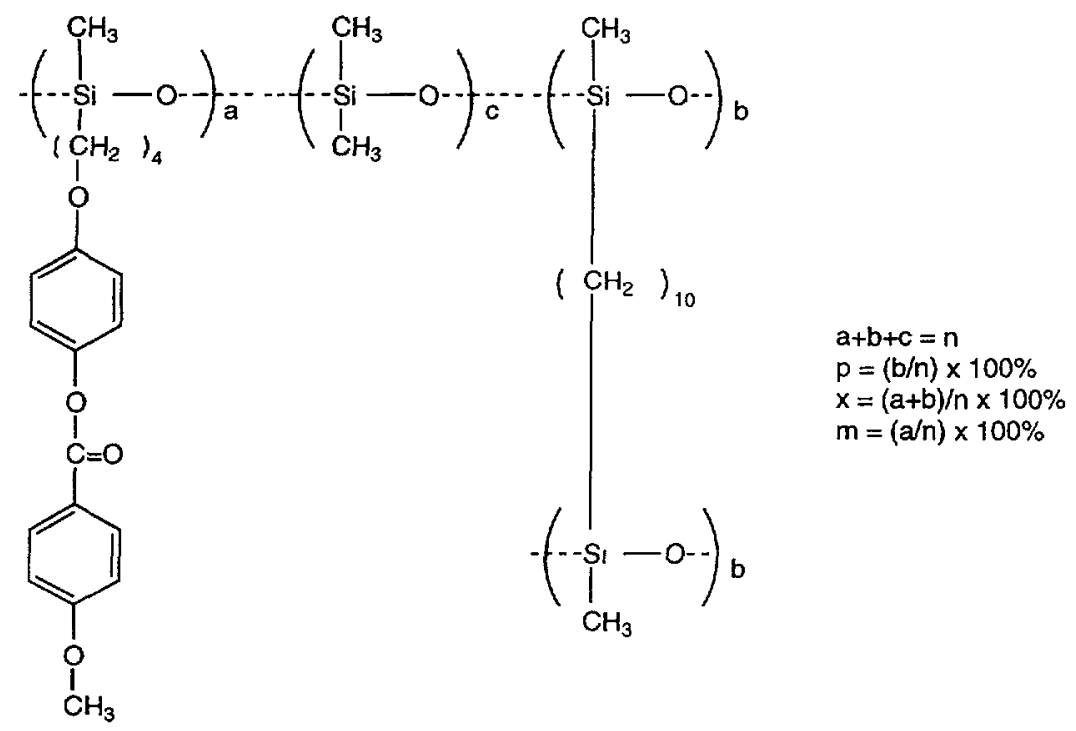

Fig. 1. - Molecular structure of the samples. Sample E4 is the only one that has element c.

rheological experiments have been reported [2-10], in spite of their importance for the establishment of a correlation between the macroscopic properties and the molecular structure of the compound.

The primary aim of the experiments reported in this article is to test the influence of the mesogen amount and the crosslinking density on the complex shear modulus. Three networks were synthesized, differing only in their mesogen amount and crosslinking density, all the other parameters being identical. A bare network (mesogen-free) was also synthesised, to act as a control compound. Measurements were taken with a piezo-rheometer, which has the advantage of being able to operate at much higher frequencies than conventional rheometers. The exceptionally broad range of available frequencies $\left(10^{-2} \mathrm{~Hz}-10^{4} \mathrm{~Hz}\right)$ makes it possible to determine the visco-elastic behavior of materials for which the empirical principle of timetemperature superposition does not apply.

This article is laid out as follows: Section 2 describes the characteristics of the networks studied, and outlines the principle of the measuring device used. The experimental results are given in Section 3, discussed in Section 4, and summarized in the conclusion, which also gives an indication of the perspectives opened up by our research.

\section{Materials and Methods}

The different networks were prepared from polysiloxane chains, substituted by mesogenic groups and cross-linked by flexible aliphatic chains with 10 carbons. The general formula of the compounds is given in Figure 1.

The precursor polysiloxanes were synthesized so as to have similar molar masses [11]. The average number degree of polymerization $(n)$, was determined from absolute tonometrical measurements. The substitution percentage $x$ was calculated from the NMR analysis of ${ }^{29} \mathrm{Si}$. The proportion of cross-links $(p)$ and mesogens $(m)$ are deduced from the respective proportions introduced during synthesis and from proton-NMR control. It should be noted that these values of $p$ are of necessity greater than the proportion of cross-links actually taking part in 
Table I. - Characterization of the networks.

\begin{tabular}{|ccccc|}
\hline sample & $n$ & $x(\%)$ & $p(\%)$ & $m(\%)$ \\
\hline E1 & $70 \pm 5$ & 100 & 5 & 95 \\
E2 & $70 \pm 5$ & 100 & 10 & 90 \\
E3 & $70 \pm 5$ & 100 & 15 & 85 \\
E4 & $85 \pm 5$ & 5 & 5 & 0 \\
\hline
\end{tabular}

Table II. - Transition temperatures and enthalpies of the networks.

\begin{tabular}{|c|c|c|c|}
\hline sample & $T_{\mathrm{g}}\left({ }^{\circ} \mathrm{C}\right)$ & $T_{\mathrm{SmA}-\mathrm{N}}\left({ }^{\circ} \mathrm{C}\right)$ & $T_{\mathrm{N}-\mathrm{I}}\left({ }^{\circ} \mathrm{C}\right)$ \\
\hline E1 & 5,0 & $73(0.07 \mathrm{~J} / \mathrm{g})$ & $93(1.2 \mathrm{~J} / \mathrm{g})$ \\
\hline $\mathrm{E} 2$ & $-2,5$ & $55(<0.01 \mathrm{~J} / \mathrm{g})$ & $78(0.7 \quad \mathrm{~J} / \mathrm{g})$ \\
\hline E3 & 5,0 & $50(<0.01 \mathrm{~J} / \mathrm{g})$ & $76(0.8 \mathrm{~J} / \mathrm{g})$ \\
\hline E4 & -120 & & \\
\hline
\end{tabular}

the network, given the inevitable presence of some ineffective cross-links (intramolecular, for example), which cannot be quantified. In the case of the mesogen-free network (E4), ${ }^{29} \mathrm{Si}$-NMR analysis was used to verify that cross-links are scattered at random among the chains. For the mesomorphic samples, the distribution of the cross-links was studied by small-angle neutron scattering, the network having first been swollen by a deuteriated solvent. Preliminary results do not appear to point to the existence of any segregation [12]. Table I gives the value of the various parameters which characterize the networks obtained.

All the elastomers were realized under the same conditions [13], and the synthesizing conditions adopted engender compounds with no particular macroscopic orientation of the mesogens. These compounds are neither crystalline nor semi-crystalline at low temperatures, and all, except $\mathrm{E} 4$, have $\mathrm{N}$ and $\mathrm{SmA}$ phases. Their transition temperatures and transitions enthalpies determined by Differential Scanning Calorimetry are given in Table II. Two-dimensional X-ray scattering was used to determine whether the mesophases were nematic or lamellar in nature. The SmA structure was established by X-ray measurements taken on samples orientated by mechanical stretching, as described in reference [14]. The layer spacing for samples E1, E2 and $E 3$ is of $34 \AA$. This spacing is identical to the one measured in the SmA phase of the non-crosslinked polymer.

These elastomers, which are $100 \%$ substituted, do not have a micro-phase separation. This effect may occur for elastomers with a low amount of mesogenic groups, as was observed in the lamellar phases of non-crosslinked mesomorphic polymers $[15,16]$.

The complex rigidity modulus $G=G^{\prime}+2 G^{\prime \prime}$ was measured as a function of frequency and temperature, using the piezo-rheometer described previously [17]. The principle of this apparatus consists in applying slight distortion to the sample by means of a piezo-electric ceramic (shear-vibration), and measuring the stress transmitted through the sample using a second piezo-electric element. The complex shear modulus of the sample is deduced from these data by calculating the stress- over-strain ratio. All the experiments were carried out using the same experimental procedure, which consisted in heating the sample, starting from ambient temperature until the rubbery plateau was seen to form. For each temperature, measurements were taken after 30 minutes of annealing. Sample was then allowed to cool down to room temperature. Measurements below room temperature were then taken upon cooling the sample until the glassy plateau occurred. The strain applied never exceeded $10^{-3}$, and all measurements were taken in the linear regime. Sample thickness was of the order of $0.3 \mathrm{~mm}$. 

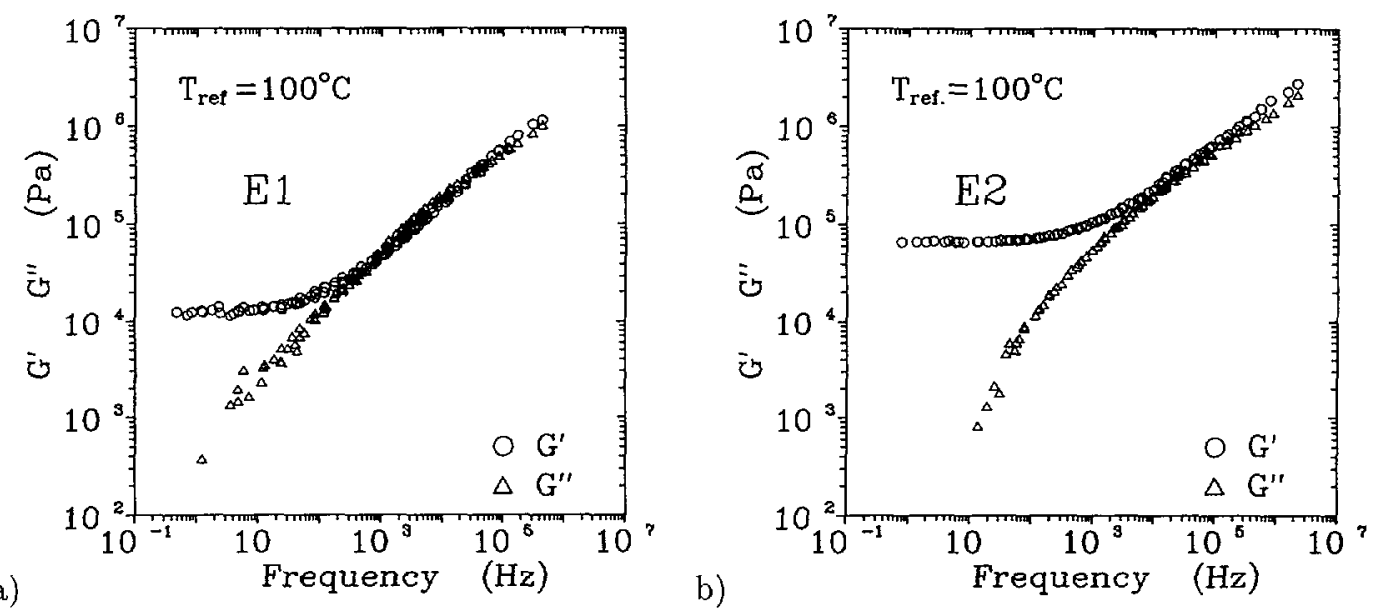

a)

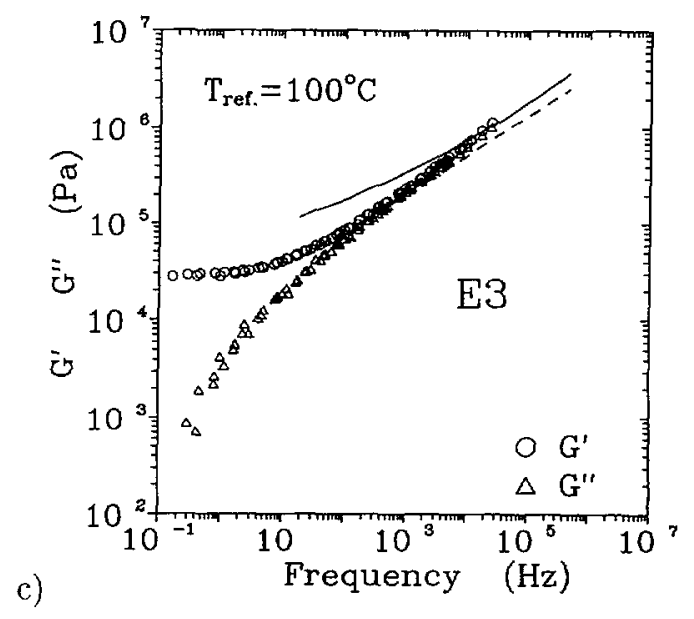

Fig. 2. - a) Master curve for sample $\mathrm{E} 1$ in its nematic and isotropic phases. Curve obtained from superimposition of measurements taken at the following temperatures: $76^{\circ} \mathrm{C}, 85^{\circ} \mathrm{C}$ (N phase) and $94^{\circ} \mathrm{C}, 100^{\circ} \mathrm{C}, 104^{\circ} \mathrm{C}, 110^{\circ} \mathrm{C}$ (I phase). b) Same as for Figure 2a but for sample E2. Curve obtained from superimposition of measurements taken at the following temperatures: $63^{\circ} \mathrm{C}, 76^{\circ} \mathrm{C}$ ( $\mathrm{N}$ phase) and $100^{\circ} \mathrm{C}, 102^{\circ} \mathrm{C}, 120^{\circ} \mathrm{C}$ (I phase). c) Master curve for sample E3 in its isotropic phase. The solid line (respectively the dashed line) represents the behavior of $G^{\prime}$ (resp. $G^{\prime \prime}$ ) determined in the nematic phase at $T=61{ }^{\circ} \mathrm{C}$ (see text for details).

\section{Results}

3.1. Master CuRves. - We have observed that the empirical principle of time-temperature superposition could be used in certain temperature ranges. Hence the data relating to the $\mathrm{N}$ and $\mathrm{I}$ phases of samples $\mathrm{E} 1$ and $\mathrm{E} 2$ can be superimposed, and give a single master curve, common to both phases. This is shown in Figures $2 \mathrm{a}$ and $2 \mathrm{~b}$, in which the master curves were generated from the data obtained in the $\mathrm{N}$ phase $\left(76^{\circ} \mathrm{C}, 85^{\circ} \mathrm{C}\right.$ for $\mathrm{E} 1 ; 63^{\circ} \mathrm{C}, 76^{\circ} \mathrm{C}$ for $\left.\mathrm{E} 2\right)$ and in the I phase $\left(94^{\circ} \mathrm{C}, 100^{\circ} \mathrm{C}, 104{ }^{\circ} \mathrm{C}, 110^{\circ} \mathrm{C}\right.$ for $\mathrm{E} 1 ; 100^{\circ} \mathrm{C}, 102^{\circ} \mathrm{C}, 120^{\circ} \mathrm{C}$ for $\left.\mathrm{E} 2\right)$. It should, however, be noted that temperature dependence of the shift factors does not follow the WLF law [18]. 

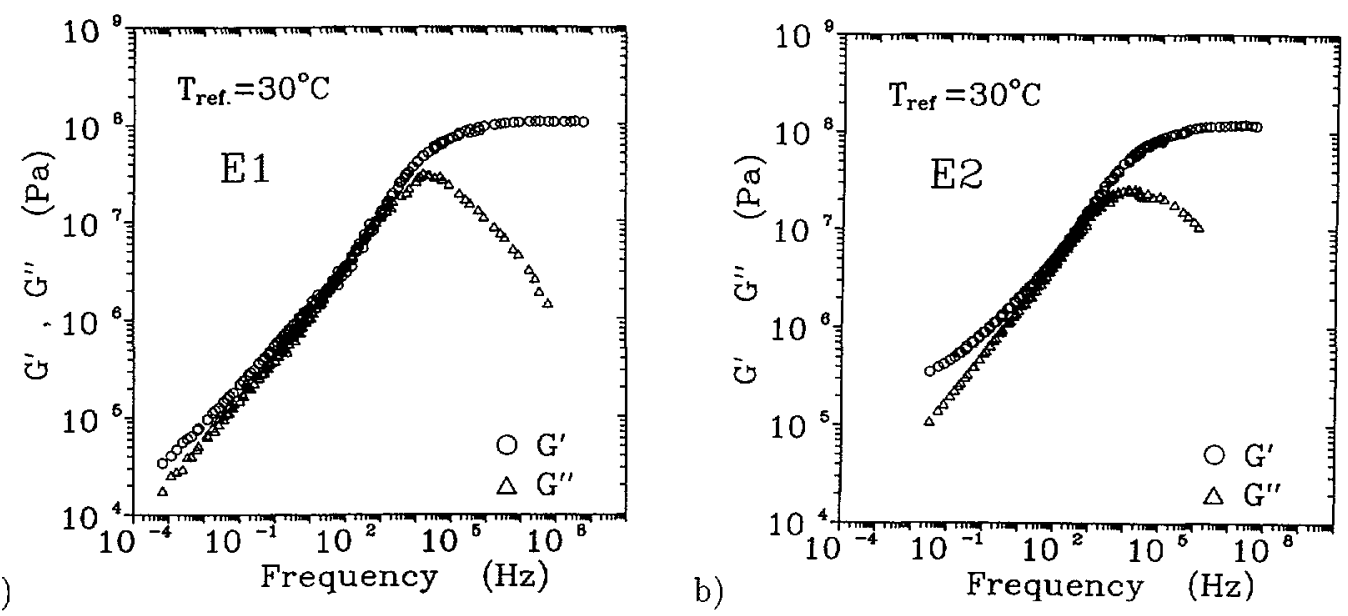

a)

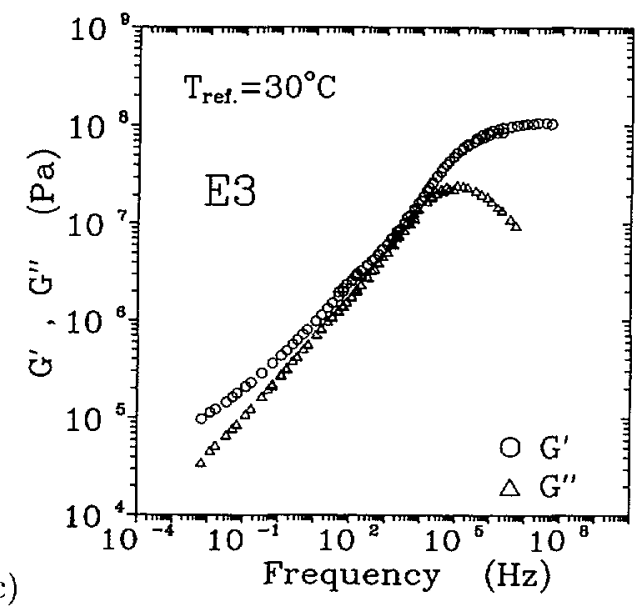

Fig. 3. - a) Master curve for sample $\mathrm{E} 1$ in its smectic-A phase. Curve obtained from superimposition of measurements taken at the following temperatures: $14{ }^{\circ} \mathrm{C}, 21{ }^{\circ} \mathrm{C}, 30^{\circ} \mathrm{C}, 39{ }^{\circ} \mathrm{C}, 52{ }^{\circ} \mathrm{C}, 61{ }^{\circ} \mathrm{C}$. b) Same as for Figure 3a but for sample E2. Curve obtained from superimposition of measurements taken at the following temperatures: $8{ }^{\circ} \mathrm{C}, 15^{\circ} \mathrm{C}, 19^{\circ} \mathrm{C}, 30^{\circ} \mathrm{C}, 40^{\circ} \mathrm{C}$. c) Same as for Figure 3a but for sample E3. Curve obtained from superimposition of measurements taken at the following temperatures: $1{ }^{\circ} \mathrm{C}, 10{ }^{\circ} \mathrm{C}, 16{ }^{\circ} \mathrm{C}, 30^{\circ} \mathrm{C}$.

Figure 3a shows that the superposition principle also allows a master curve to be drawn in the SmA phase of compound E1, but this curve cannot be superimposed on the master curve in Figure 2a, associated with the $\mathrm{N}$ and I phases. The same is true for sample E2, the $\operatorname{SmA}$ phase master curve of which is shown in Figure $3 \mathrm{~b}$. These two samples therefore have two master curves: one for $T>T_{\mathrm{AN}}$ and the other for $T<T_{\mathrm{AN}}$.

The behavior of sample E3 is different, as the $\mathrm{N}$ phase data cannot be superimposed on those from the I phase. This is illustrated by Figure $2 \mathrm{c}$, which shows the results obtained in the $N$ phase at $T=61^{\circ} \mathrm{C}\left(G^{\prime}\right.$ solid line; $G^{\prime \prime}$ dashed line) and in the I phase $\left(76^{\circ} \mathrm{C}, 94^{\circ} \mathrm{C}\right)$. This result will subsequently be seen to be due to a marked influence of pre-transitional effects associated with the N-SmA transition. Figure $3 c$ shows that a master curve can be drawn for 

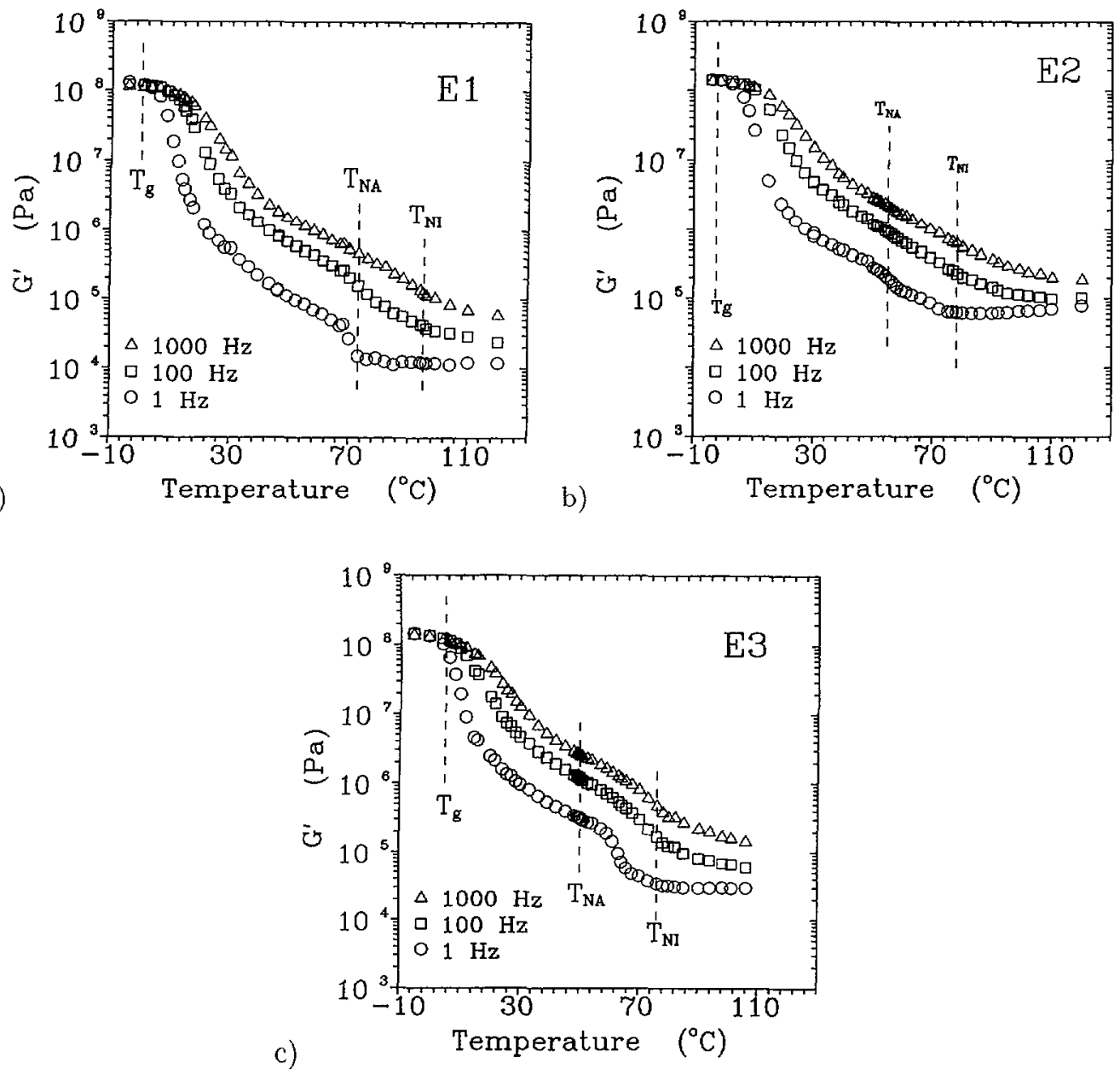

Fig. 4. - a) Temperature dependance of the storage modulus $G^{\prime}$ measured at $1 \mathrm{~Hz}, 10 \mathrm{~Hz}$ and $1000 \mathrm{~Hz}$ for sample E1. The vertical lines indicate the phase transition temperatures as determined by DSC. b) Same as Figure 4a but for sample E2. c) Same as Figure 4 a but for sample E3.

the SmA phase. This latter cannot be superimposed on that corresponding to the I phase, as has already been observed for samples E1 and E2.

In order to simplify subsequent comparisons of the behavior of the various samples, the master curves have been normalized to a common reference temperature $T_{\text {ref }}$ of $100^{\circ} \mathrm{C}$ for the I phase and $30^{\circ} \mathrm{C}$ for the $\mathrm{SmA}$ phase.

3.2. Variation of $G^{\prime}$ With the Temperature. - Figures $4 \mathrm{a}, 4 \mathrm{~b}$, and $4 \mathrm{c}$ show the temperature variations of the real part of the rigidity-modulus of samples E1, E2 and E3 respectively. For each sample, we have plotted the results obtained at $1 \mathrm{~Hz}, 100 \mathrm{~Hz}$ and $1000 \mathrm{~Hz}$.

These three figures show that, essentially, $G^{\prime}$ behavior is controlled by the glass transition. The extent of the effects associated with this transition is given by the temperature at which. for a given frequency, the loss tangent becomes 0 . For all three samples, the temperature measured at $1 \mathrm{~Hz}$ is of the order of $T_{\mathrm{g}}+100^{\circ} \mathrm{C}$. The thermal behavior of $G^{\prime}$ is regular, except 


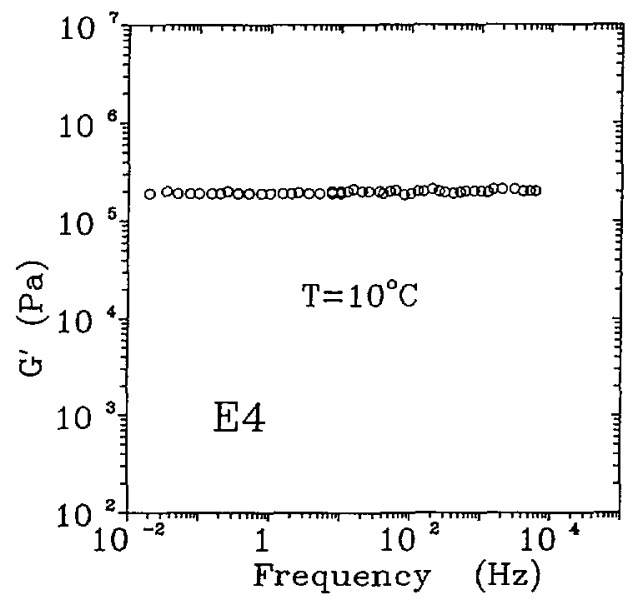

Fig. 5. - Storage modulus $G^{\prime}$ against frequency for mesogen-free sample E4.

in the vicinity of the $\mathrm{N}$-SmA transition at the lowest frequency. This anomaly is characterized by an increase of $G^{\prime}$ which appears as temperature decreases, either in the $\mathrm{N}$ phase (sample E3) or at the transition (sample E1). It should be noted that no anomaly is observable at the N-I transition.

\section{Discussion}

4.1. Master Curves. - The fact that data associated with the $N$ and I phases for compounds E1 and E2 can be related stems from the absence of any critical effects at the N-I transition, and the fact that those associated with the N-SmA transition are negligible in the $\mathrm{N}$ phase. The second condition is not realized for compound $\mathrm{E} 3$, and this explains that the results obtained at $61^{\circ} \mathrm{C}$ in the $\mathrm{N}$ phase cannot be superimposed on those obtained in the I phase.

The absence of a master curve common to all three phases (N, I, and SmA) stems from the fact that smectic elastomers are special systems with two characteristic lengths: the distance between reticulation points and the distance between the smectic layers.

Figures $2 a, 2 b$, and $2 c$ enable the characteristic frequency of the longest visco-elastic mode to be determined. A rough estimation of this value is given by the interception of the two straight lines associated with variations of $G^{\prime}$ in the elastic and visco-elastic regimes respectively. The frequency thus obtained is of the order of $50 \mathrm{~Hz}$ for sample $\mathrm{E} 1,600 \mathrm{~Hz}$ for sample E2 and $10 \mathrm{~Hz}$ for sample $\mathrm{E} 3$.

4.2. Influence of the Mesogen amount on the Mechanical Properties of the NETWORKS. - In order to determine this influence, it is necessary to compare the response of one of the networks to that of the network without any mesogens (E4). This comparison must be made at temperatures $T$ for which the difference $T-T_{\mathrm{g}}$ is comparable from one sample to another. It will be made on the basis of sample $\mathrm{E} 1$, which has the same crosslinking density as $\mathrm{E} 4(p=5 \%)$ and a mesogen amount of $95 \%$.

Figure 5, which concerns sample E4, shows that this compound has an elastic response throughout the whole range of frequencies studied, with a rigidity modulus $G_{0}$ of the order of 
$2.0 \times 10^{5} \mathrm{~Pa}$. Figure $2 \mathrm{a}$ shows that the elastic behavior of sample $\mathrm{E} 1$ is quite different, being elastic at low frequencies and visco-elastic at high frequencies. Furthermore, its static rigidity modulus can be seen to have a much lower value $\left(G_{0} \approx 1.3 \times 10^{4} \mathrm{~Pa}\right)$ than that of $\mathrm{E} 4$. These observations therefore show that the mechanical properties of mesomorphic networks are not determined solely by reticulation of the principal chain, but also depend on the presence of mesogens.

4.3. Influence of the Crosslinking Density $(p)$ on the Mechanical Properties of THE NETworks. - Comparing Figures 2a (Sample E1), 2b (Sample E2), and 2c (Sample $\mathrm{E} 3$ ) shows that the value of $G_{0}$ is roughly proportional to $p$ for $\mathrm{E} 1\left(G_{0} \simeq 1.3 \times 10^{4} \mathrm{~Pa}\right.$ ) and E3 $\left(G_{0} \simeq 3.0 \times 10^{4} \mathrm{~Pa}\right)$, but that determined for $\mathrm{E} 2\left(G_{0} \simeq 7.0 \times 10^{4} \mathrm{~Pa}\right)$ is abnormally high. This value was checked for another sample with identical characteristics, but synthesized separately. Above the rubbery plateau, all three samples are seen to have similar dynamic behavior, characterized by an $\omega^{0.44}$ increase of $G^{\prime}$ and $G^{\prime \prime}$ in the frequency range available.

The fact that the static rigidity modulus $G_{0}$ of the various mesomorphic networks is weaker than that of the mesogen-free network would suggest that not all of the cross-links contribute to the construction of the network. The presence of mesogens can, in fact, create steric obstacles which inhibit the phenomenon of reticulation during synthesis. This phenomenon is no doubt exacerbated by the fact that the length of the crosslinks, in their maximum-stretch configuration, is of the order of $13 \AA$, less than that of the mesogens (18 $\AA$ ).

As above, it may also be possible to explain the abnormal variation of $G_{0}$ as a function of $p$ by reference to competition between the chains which constitute the cross-links and the mesogens, which, according to the case considered, would lead to a greater or lesser proportion of effective cross-links.

Influence of the crosslinking density can also be observed in the SmA phase of each of the three samples. Figures 3a (Sample E1), 3b (Sample E2), and 3c (Sample E3) do indeed show that the frequency relative to the position of the peak associated with $G^{\prime \prime}$ varies from one sample to another. This frequency corresponds to $\simeq 30 \mathrm{kHz}$ for $\mathrm{E} 1, \simeq 20 \mathrm{kHz}$ for $\mathrm{E} 2$, and $\simeq 100 \mathrm{kHz}$ for $\mathrm{E} 3$. The width of the peak can also be seen to be greater for $\mathrm{E} 2$ than for the other two samples. These two observations confirm the unusual behavior of $E 2$. On the other hand, at the glassy plateau, all three samples share the same value of $G^{\prime}\left(G^{\prime} \simeq 10^{8} \mathrm{~Pa}\right)$, which can thus be seen to be independent of $p$.

Finally, it should also be noted that the Kerr-effect measurements taken in the isotropic phase of various non-crosslinked liquid-crystal polymers have shown that mesogen orientation is characterized by a single-time relaxation mechanism $[19,20]$. In elastomers, this single time may be replaced by a relaxation time distribution. This arises from the fact that all the mesogens do not share the same possibility of reorientation within the network, due to the aforementioned unwanted intramolecular crosslinks and steric obstacles.

4.4. Behavior at THE $N$ - SmA Transition. - We shall begin by discussing the decrease of $G^{\prime}$ observed at $1 \mathrm{~Hz}$ in the SmA phase of sample E1 (Fig. 4a). If the N-SmA transition is second-order (or weakly first-order), as suggested by the low value of the enthalpy of transition, then this decrease corresponds to a pre-transitional effect, which may be associated with the softening of the smectic layers. The fact that this effect is observable indicates that these measurements correspond to the $\omega \tau<1$ regime, where $\tau$ is the critical relaxation time associated with the transition.

This decrease of $G^{\prime}$ is not apparent in the measurements taken at the same frequency $(1 \mathrm{~Hz})$ in the SmA phase of sample E3 (Fig. 4c). If the transition is assumed to be of the second order, then this change in behavior indicates that the measurements correspond to the $\omega \tau \gg 1$ 
regime, in which smectic order-parameter fluctuations are frozen. In this regime the $N$ phase can be identified with the $S m A$ phase, and this explains why the values of $G^{\prime}$ determined in the $\mathrm{N}$ phase are a prolongation of those in the SmA phase, before decreasing for those temperatures which are farthest from the transition. This behavior cannot occur for a first-order transition. The same reasoning can also be applied to the $\mathrm{N}-\mathrm{SmA}$ transition of sample E2. The fact that the curves giving the behavior of $G^{\prime}$ at higher frequencies $(100 \mathrm{~Hz}, 1000 \mathrm{~Hz})$ show no marked anomalies for any of the three samples indicates that the critical relaxation time is very long.

\section{Conclusion}

Side-chain mesomorphic networks display original dynamic behavior which is very different from the purely elastic behavior observed with the same conditions on the bare-network. The presence of mesogens shows up essentially in the existence of marked visco-elastic effects occurring in all phases, including the isotropic phase, as well as in a softening of the network. Although the behavior observed is complex, our measurements have enabled a certain number of characteristic parameters to be determined (high- and low-frequency rigidity moduli, the frequencies associated with the longest relaxation mode and with the glass transition). They have also shown that the N-SmA transition presents critical effects with extremely long characteristic times. On the other hand, no critical effect associated with the N-I transition was observed, even at the lowest frequency. Finally, it should be noted that all the phases are under the influence of the dynamic glass transition, which has a range of the order of $100^{\circ} \mathrm{C}$ for a frequency of $1 \mathrm{~Hz}$.

All the networks studied here have a substitution degree of $100 \%$. leading to a very high proportion of mesogens $(>85 \%)$. Future rheology experiments should be carried out on networks with much lower mesogen amount. This would allow a higher degree of mesogen independence, which should in turn lead to a modification of visco-elastic behavior, and perhaps to the observation in the master curves of the characteristic frequency associated with a cooperative orientation of the mesogens. It would also be useful to synthesize samples with $\mathrm{N}$ and I phases only, thus avoiding the critical effects associated with the $\mathrm{N}-\mathrm{SmA}$ transition, which modify the response of the compound. A quantitative study of the N-SmA transition would require a network with a much larger temperature difference between $T_{\mathrm{g}}$ and $T_{\mathrm{NA}}$ than was the case for our compounds, in order to do away with effects associated with the glass transition.

\section{References}

[1] See for example: Gleim W. and Finkelmann H., in "Side-chain Liquid crystal polymers", C.B. Mc Ardle Ed. (Blackie and Son Ltd., 1989) p. 287: Meier W. and Finkelmann H., Cond. Matter News 1 (1992) 15; Zentel R., Adv. Mater. 10 (1989) 321.

[2] Oppermann W., Braatz K., Finkelmann H., Gleim W., Kock H.J. and Rehage G., Rheol. Acta 21 (1982) 423.

[3] Schätzle J., Kaufhold W. and Finkelmann H., Makromol. Chem. 190 (1989) 3269.

[4] Hammerschmidt K. and Finkelmann H., Makromol. Chem. 190 (1989) 1089.

[5] Barnes N.R., Davis F.J. and Mitchell G.R., Mol. Cryst. Liq. Cryst. 168 (1989) 13.

[6] Kaufhold W. Finkelmann H. and Brand H.R., Makromol. Chem. 192 (1991) 2555.

[7] Deeg F.W., Diercksen K., Schwalb G., Bräuchle C. and Reinecke H., Phys. Rev. B 44 (1991) 2830 . 
[8] Pakula T. and Zentel R., Makromol. Chem. 192 (1991) 2401.

[9] Sigel R., Stille W., Strobl G. and Lehnert R., Macromolecules 26 (1993) 4226.

[10] Brehmer M. and Zentel R., Mol. Cryst. Liq. Cryst. 243 (1994) 353.

[11] Leroux N., Mauzac M., Noirez L. and Hardouin F., Lrq. Cryst. 16 (1994) 421.

[12] Charlassier A.M., Boué F. and Mauzac M., work in progress.

[13] Degert C., Richard H., Mauzac M., Mol. Cryst. Liq. Cryst. 214 (1992) 179.

[14] Degert C., Davidson P., Megtert S., Petermann D. and Mauzac M., Liq. Cryst. 12 (1992) 779.

[15] Nguyen H.T., Achard M.F.. Hardouin F., Mauzac M., Richard H. and Sigaud G., Lrq. Cryst. 7 (1990) 385.

[16] Diele S., Oelsner S., Kuschel R., Hisgen B., Ringsdorf H. and Zentel R., Makromol. Chem. 188 (1987) 1993.

[17] Gallani J.L., Hilliou L., Martinoty P. and Keller P., Phys. Rev. Lett. 72 (1994) 2109.

[18] Ferry J.D., Viscoelastic Properties of Polymers, third edition (Wiley, 1980).

[19] Reys V., Dormoy Y., Gallani J.L., Martinoty P., Le Barny P. and Dubois J.C., Phys. Rev. Lett. 61 (1988) 2340.

[20] Reys V., Dormoy Y., Collin D., Keller P. and Martinoty P., J. Phys. II France 2 (1992) 209. 